parent. In your leading article (17 August, p. 430) you express an opinion that was discarded by most ophthalmologists in Britain many years ago. Your support for this delayed surgery is perpetuating an idea which results in many children not developing any form of binocular vision and is performing a grave disservice to squinting children.-I am, etc.,

BARRIE JAY

Moorfields Eye Hospital,

\section{Tuberculous Lymphoedema}

SIR,-In their report of two cases of tuberculous lymphoedema (28 September, p. 786) Dr. Shaista Hoda and Professor S. M. Rab describe this condition as rare. That this is not everywhere the case is shown by Professor Anomah Ngu, ${ }^{1}$ who reported from Ibadan a study of 65 patients with chronic lymphoedema investigated by lymph node biopsy, lymphangiography, examination of blood films for microfilaria, skin tests for filarial antigens, and the Heaf and Frei tests. In 25 of his patients the lymphoedema was caused by turberculous adenitis and in 30 by chronic pyogenic infection. In no case was Wucheria bancrofti found.

Though I have no records available, my own experience of patients with elephantiasis of the leg or scrotum seen in Northern Ghana was in accordance with these findings.-I am, etc.,

Liverpool

F. L. AsHWORTH

$1 \mathrm{Ngu}, \mathrm{V}$. A., in Companion to Surgery in Africa,

ed. W. W. Davey. London, Livingstone, 1968.

\section{Price of Prostatectomy}

SIR,-Since a substantial proportion of the endoscopic prostatectomies (and a lesser proportion of the open prostatectomies, for I am an enthusiastic resectionist), reported by Mr. Argyrou and others (24 August, p. 511) were in fact under my care, I feel particularly entitled to comment both on the article itself and on the letters from $\mathrm{Mr}$. R. S. Murley and Mr. P. F. J. Hickinbotham (21 September, p. 739).

First of all I deprecate the concept that a short postoperative stay is necessarily a good thing. Patients should stay in hospital as long as they need, and I am miserably aware that most of ours are sent home far too early. A mean figure of eight days for an admission which includes a prostatectomy is much too small and, rather than attraoting praise, should be seen as a lamentable failure of the National Health Service to provide the patient with an adequate servioe. Furthermore, I am not anxious to be seen by my patients or my employing authority as a purveyor of cheap prostatectomy. I very much hope that as a trained urologist I have more to offer them. Indeed some urologists are indifferent reseotionists, as Mr. Murley has found out; they are nonetheless important or valuable people for that.

The essential difference between endosoopic and open prostatectomy to the patient is that the former does not involve an abdominal incision and the consequent postoperative pain. This simple and obvious fact is often overlooked but ortainly seems to place the onus upon the open prostatec- tomist to demonstrate that his operation is better in cases where either procedure is appropriate. No attempt to do this has been made by your correspondents.

Lastly, Mr. Hickinbotham has his horse and cart in the wrong order. Those urologists who offer open prostatectomy to the patient with a large gland and endoscopic prostatectomy to those with a smal gland often observe that the open operation is better. The reason is that patients with a large gland have a more favourable condition to treat than those with a small gland and tend to do better whether they are managed by endoscopic or open prostatectomy. Let Mr. Hickinbotham resect a little faster and tackle the larger glands. He will find himself, and his patients, most pleasantly rewarded.-I am, etc.,

Cosham, Hants

G. F. ABERCROMBIE

\section{"Lost Threads" with Intrauterine Devices}

SIR,-This common problem is handled in a number of ways by gynaecologists and family planning doctors, with varying success and often some discomfort to the patient. The diagnosis is frequently in doubt; some are cases of unrecognized expulsion and some of in situ pregnancy in which the threads of the device have been drawn up by the enlarging uterus. More rarely the device may have perforated the uterus, with or without subsequent pregnancy. Most commonly the cavity of the non-pregnant uterus contains both the device and its threads owing to alteration of the position of the former.

The risk of early pregnancy limits the usefulness of $x$-rays, and even if two views are taken they may fail to establish the true location of the device. We have found that in expert hands ultrasonic B-scan is preferable as the uterus can be outlined in relation to the device. But the method described below is now preferred as the first step in many cases where pregnancy is not suspected-ideally during a period-as diagnosis and treatment can be virtually simultaneous.

In this department we have recently been using 4-mm disposable vacuum aspiration curette (Rocket) for biopsy of the endometrium and have found that it is also extremely useful for bringing out the missing threads of intrauterine devices. out the missing threads of intrauterine devices. cervix through a duck-billed speculum a singletoothed tenaculum is applied and the uterus sounded. The adaptor on the aspiration catheter is fitted to the small specimen bottle provided and connected to pressure tubing linked to any appropriate source of vacuum. We have found the R4.910 (Rocket) hand pump very satisfactory, operated by an assistant. The soft plastic cathete uterine cavity and suction applied (approximately $50 \mathrm{~cm} \mathrm{H} \mathrm{H}_{2} \mathrm{O}$ is sufficient). The catheter is then $50 \mathrm{~cm} \mathrm{H}_{2} \mathrm{O}$ is sufficient). The catheter is then (or threads, depending on the type of device) is usually brought out at the first attempt. The device should then be removed as its position is likely to have been disturbed, and a replacement device can be inserted.

The method appears to cause much less discomfort than alternative outpatient procedures using exploratory forceps or endometrial biopsy curettes. However, in nullipara and certain othe patients in whom dilatation (to Hegar 4 only) may be required local anaesthesia of the cervix by injection of $1 \%$ lignocaine plus adrenaline at the
12,4 , and 8 'clock positions may be indicated.

The technique as described here is rapid and rarely requires the lithotomy position or any form of anaesthesia. The risk of damage to the uterus is especially low as the catheter used is soft and flexible. The apparatus is simple, presterilized, and portable and requires no electric power. The method may thus be considered for use by trained personnel in the normal family planning clinic context.-We are, etc.,

\section{JOHN GUILLEBAUD}

J. KASONDE

Nuffield Department of Obstetrics and Gynaecology,

John Radcliffe Hospital, Oxford

\section{Fatal Puerperal Septicaemia}

SIR,-Reports to the Public Health Laboratory Service cited by you (17 February 1973, p. 428) illustrated the tendency of group $B$ streptococci to act as serious pathogens in women after delivery and in newborn infants. It has been suggested that all pregnant women in the last trimester should be screened for the existence of group B streptococci in the vagina and the carriers adequately treated, ${ }^{1}$ but the justification for this recommendation has subsequently been questioned. ${ }^{2}$ The carrier rate of the more pathogenic streptococci-for instance, those belonging to group A-is probably much below that of group B streptococci, but the former should not be omitted from the ourrent discussion. The clinical course of an infection with haemolytic streptococci often includes septic shock with coagulopathy. Disseminated intravascular coagulation has been described as a consequence of an overwhelming infection, ${ }^{3}$ but a generally increased fibrinolytic activity may also play an important role in the pathogenesis of the clinical syndrome, as exemplified by the following case.

A 24-year-old healthy primigravida was admitted to the delivery ward in the 40th week of an uneventful pregnancy after spontaneous rupture of the membranes. After eight hours' normal labour she was delivered with a vacuum extractor of a she was delivered with a vacuum extractor of a
child with an Apgar score of 9 . During the labour child with an Apgar score of 9. During the labour the patient's temperature rose to $38^{\circ} \mathrm{C}$ but fell
to normal after salicylate administration. Twelve to normal after salicylate administration. Twelve hours after delivery the patient became ill, vomited,
and had a rising temperature and tachycardia. Within one hour the clinical picture of septic shock was evident. The platelet count was 90,000 $\mathrm{mm}^{3}$, the AHF antigen (immunochemical method) was strongly elevated $(1,090 \%)$, while AHF activity was reduced (42\%). The fibrinogen level was low $(0 \cdot 15 \mathrm{~g} / 100 \mathrm{ml})$ and Owrens $\mathrm{P}$ and $\mathrm{P}$
$(65 \%)$ and factor V $(23 \%)$ were both markedly reduced. The patient had a high fibrinolytic activity in plasma (Schneider's test), an extremely high level of fibrinogen degradation products (end products: $D$ and $E)$ in the serum $(1,000 \mu \mathrm{g} / \mathrm{ml})$, a positive ethanol gelation test, and low antitrombin III $(44 \%)$ and $\alpha_{2}$-macroglobulin $(30 \%)$ levels. units/ml plasma) was obtained. The laboratory tests, which were available only in part at the acute stage, thus showed a strong activation of both the coagulation and fibrinolytic systems.

The following treatment was given: synthetic plasma expander (Hemacel), plasma, fresh blood, and high-molecular-weight $(74,000)$ dextran, $0.01 \mathrm{~g} / \mathrm{kg}$ body weight tranexamic acid, $5 \mathrm{~g}$ ampicillin, $250 \mathrm{mg}$ hydrocortisone, and $80 \mathrm{mg}$ betamethasone. The patient's condition deteriorated rapidly, she went into coma, became excessively acidotic, and an adequate blood pressure could not be maintained. She died 19 hours after delivery. be maintained. She died 19 hours after delivery. At necropsy marked acute inflammation was found in the uterine wall with beginning abscess formation. Fibrin thrombi were present in the vessels of the
lungs and the kidneys, and the surfaces of the $a b-$ dominal organs showed a tendency to generalized bleeding. Abundant growth of haemoly tic streptococci group A, sensitive to penicillin, was obtained in cultures from the vagina, uterus, liver, and spleen.

The condition of the baby was initially satisfactory but deteriorated at 12 hours age with the 